\title{
Las canteras de mármol de Macael. De "libres y comunes a todos" a bienes municipales
}

\author{
A. Carretero Gómez y J.A. Aznar Sánchez \\ Universidad de Almería, Departamento de Economía y Empresa, 04120 Almería \\ acarrete@ual.es
}

RESUMEN

La suerte de los habitantes de Macael ha estado unida al mármol desde tiempo inmemorial. El alcance del recurso desborda las fronteras locales: durante los últimos años del pasado siglo en el entorno de Macael se extraía más del $40 \%$ del mármol nacional, siendo España uno de los líderes mundiales del mercado de esta piedra ornamental. Este artículo analiza los cambios que se han producido en el sistema de acceso a las canteras desde 1573, año en el que se realizó el apeo de la villa de Macael, hasta la actualidad. Tras no pocas vicisitudes, en las que el pueblo de Macael ha tenido que defender la propiedad sobre las canteras, tanto frente a intereses particulares como de la administración pública, los bienes que eran comunales, y por ello de libre acceso para los lugareños, pasaron a ser propiedad del Ayuntamiento, que en la actualidad es también titular de la concesión de explotación del mármol, y la arrienda a los empresarios que desean extraer el mineral.

Palabras clave: canteras, historia, Macael, mármol, propiedad.

\section{The marble quarries of Macael. From "free and communal" to council property}

\begin{abstract}
The fate of the inhabitants of Macael has been closely linked to the production of marble from time immemorial. The scope of these resources transcended local borders during the latter part of last century; thus, in the last few years, the marble extracted from the surroundings of Macael accounted for over $40 \%$ of the national production, with Spain being one of the leading world producers of this ornamental rock. This paper analyzes the changes that have taken place in the quarry access system since 1573, when the town of Macael was surveyed, up to the present time. After many historical changes in which the people of Macael have had to fight for ownership of the quarries, both against private interests and public administration, the assets which were communal, and therefore freely accessible to the locals, became the property of the Local Council, which at present also holds the exploitation concession of the marble resources and the power to grant leases to entrepreneurs wishing to extract this mineral.
\end{abstract}

Keywords: history, Macael, marble, ownership, quarries.

\section{ABRIDGED ENGLISH VERSION}

\section{Introduction}

The extraction and processing of marble in Macael have been from time immemorial much more than mereIy a way to earn a living. In the early centuries of our era, the Romans used marble for paving and tombstones, sculptures, columns and capitals; the most relevant samples being found in Itálica and in the Roman Theatre of Mérida. The Arabs promoted the exploitation of the quarries between the tenth and eleventh centuries, using marble in, amongst other constructions, Medina-Azahara and the Alhambra in Granada. An outstanding feature of the latter monument is the Courtyard of the Lions, where the columns and capitals, fountain and sculptures were made out of white marble from Macael. In later centuries, Macael marble was still sought after to embellish palaces and cathedrals. We can admire it, for example, in the Escorial Palace and 
the Royal Palace in Madrid. When the twentieth century gave way to the twenty first, the surroundings of Macael were yielding over $40 \%$ of the Spanish marble, making Spain one of the leading world producers of this mineral.

\section{Results}

Behind the present access system to the quarries there is a long history. In the book that describes the survey carried out in the town of Macael in 1573, we learn that the marble quarries "have always been freely available and communal to all."This text, which left no doubt about this custom until the present time, has sustained the people of Macael in their fight for ownership of the quarries both against private interests and public administration from then until almost the present day.

For centuries, the utilization of marble followed the operation scheme of communal property. Free access to resources presented no particular difficulties: the quantity available was substantial, the volume of extraction did not represent any risk of depletion with regard to the resources and the co-proprietors, who were not many, generally adhered to the basic rules imposed by tradition. The Local Council was merely in charge of resolving any conflicts that occurred and protecting the interests of third parties or institutions.

The new legal and administrative system, a consequence of the political and social changes that took place in the first decades of the twentieth century, brought about relevant changes in all areas. One of the consequences for Macael was that the mountains became owned property, which enabled the Local Council to restrict free access, to start organizing auctions to utilize the mineral and to demand taxes from those who obtained mining licenses.

Almost simultaneously, and faced with the urgent need for money to fund the Government s expenses and debts, confiscating provisions became of the utmost importance, a practice that lasted well into the twentieth century. While owned property was initially targeted, by the middle of the century communal property was also included; unless it could be proved that it was a necessity for the people. For over half a century the Macael Council played a double game, managing to avoid the sale of the mountains, strongly proclaiming before the higher echelons of the Administration their communal nature and the people s essential need for them, while at the same time obtaining an income from utilizing them as its own property.

In 1920 an auction took place, which would have a lasting impact on the life of the town due to its characteristics (among them, the issue of permits which would allow the extraction of marble for 20 years); many believed that this severely mortgaged the resources of the area causing damage to its inhabitants. After constant disagreements, complaints and accusations, the Local Council decided to grant the contract strictly to the highest bidder, arguing that some rules had not been observed.

Around the same time, one of the main Macael entrepreneurs, Antonio Ortiz, claimed ownership of some quarries that had been exploited by his family since 1887; he invoked the right acquired by over 30 years of continued occupation. Disregarding the fact that he had obtained the right to perennial exploitation whilst being Mayor of the town, the Directorate-General of Taxation (Dirección General de Contribuciones e Impuestos) granted his request. In the difficult year of 1936, the heirs of Antonio Ortiz renounced the exploitations in favour of the people.

When the Spanish Civil War ended, claims to ownership of and the right to use the quarries were reactivated. The courts of law ruled in favour of the highest bidder in the 1920 auction, but the political powers refused to hand the quarries over to him so that he would be able to continue extracting marble for the remaining years, when the Local Council terminated the contract. The Ortiz family, however, was denied by the court of law in 1947 the right to ownership they were claiming. Among other reasons, this decision was based on "rights whose more or less remote origins often stem unfortunately from actual usurpation and the splitting of lands belonging to communal mountains".

The Mines Act of 1944 established that rocks, and therefore, marble, can be utilized by the owners of the lands where the quarries are located as if the resources belonged to them or they can grant exploitation permits to others. It also stipulated that when quarries exist in lands of public use and domain their exploitation is communal and a permit from the appropriate authority is required for this purpose. The Macael Local Council, as owner of the quarry lands and under the above Act, granted exploitation licenses so that any neighbour could start exploiting a quarry just by applying for the appropriate permit and paying for the rights to the materials extracted.

The Mines Act of 1973, which replaced that of 1944, allowed an improvement in the order of exploitation and rationalized the utilization of resources. On this occasion a planimetric survey of the mountains was carried out and the perimeter of each quarry was accurately defined. Under this Act, the Local Council consolidated its rights over the quarries obtaining the concession to exploit them, which it partially leased to those wishing to extract the mineral. 
Towards the end of last century, the Macael Local Council was the owner of seven licenses for the extraction of marble (Macael North, Macael South, Macael East, Milagrosa, Segunda Milagrosa, San Andrés y Blanco Macael III) and of two research permits (both with the name Blanco Macael). Concessions occupy most of the municipal district and stretch into other districts.

The activity in the quarries during the last two decades is defined by the Overall Action Plan (Plan de Actuación Global) which was first implemented in the area in 1983 in order to put an end the severe crisis that the sector was going through. The Plan, initially fostered by the Institute of Industrial Promotion of Andalusia (Instituto de Promoción Industrial de Andalucía), and later continued until its demise in the early nineties by the Institute of Development of Andalusia (Instituto de Fomento de Andalucía), was supported by all the agents in the sector and succeeded in solving or handling many of the problems that had been affecting the marble industry for a long time. The industrial restructure advanced by the Plan, and in particular, the implementation of the Macael Mountain Range Director Plan (Plan Director de la Sierra de Macael), was an important step in modernizing exploitation.

The fight for ownership of the quarries came to an end in the middle of the twentieth century with the ruling of the Granada High Court of 1947. The Mines Act of 1973 allowed the Macael Council to secure its rights in the area, obtaining the ownership of licenses to extract mineral, whilst the Overall Action Plan of the nineteen eighties harnessed many of the problems that had been affecting the sector, although, naturally, it did not immunize it against further crises. At present, the battle continues on other fronts, such as production and commercialization.

\section{Introducción}

La extracción y la elaboración del mármol son para Macael, desde tiempo inmemorial, mucho más que un medio de subsistencia. Hablar de Macael lleva necesariamente a hablar del mármol $y$, en no pocos ámbitos, tratar del mármol obliga a citar a Macael. La suerte de sus habitantes ha estado siempre unida a los avatares de este recurso natural; a lo largo de los siglos se han alegrado o han sufrido siguiendo los altibajos de la actividad en las canteras que, como cualquier actividad económica, ha pasado por periodos de esplendor y por épocas de crisis.

Cuando el siglo XX daba paso al XXI, en Almería la industria del mármol pugnaba con la industria ligada a la agricultura por el liderazgo del sector secundario. Pero el alcance del recurso desborda las fronteras locales: durante esos años en el entorno de Macael se extraía más del $40 \%$ del mármol nacional (Estadística Minera de España), siendo España uno de los líderes mundiales de este recurso, y la comarca del Mármol, en la que se concentran las actividades extractivas y elaboradoras, era una de las pocas comarcas interiores de Andalucía que crecía en actividad y población.

El actual sistema de acceso a las canteras está precedido de una historia de siglos. En el libro que recoge el apeo que se llevó a cabo en la villa de Macael en el verano de 1573 se lee que se apearon "las canteras que son de mármol... y se declaró por el seyse que siempre han sido libres y comunes a todos". Este texto, que dejaba clara la costumbre hasta el momento, ha servido al pueblo de Macael para defender, desde entonces y casi hasta nuestros días, su propiedad sobre las canteras, tanto frente a los intereses de particulares (en muchos casos, del propio lugar) como de la administración pública.

Con el paso del tiempo la situación ha ido cambiando $y$, tras no pocas vicisitudes, los bienes que eran comunales, y por tanto de libre acceso para los lugareños, pasaron a ser propiedad de la administración local, que regula la actividad que se desarrolla en ellos. Actualmente el Ayuntamiento, además de propietario de los terrenos, es titular de la concesión de explotación del mármol, y la arrienda a los empresarios que quieren extraer el mineral.

\section{Antecedentes}

La historia del ser humano está unida desde sus inicios a la utilización de la piedra. Al principio se usó, con una elaboración muy pobre, para hacer instrumentos y utensilios de uso cotidiano; después, algo más trabajada, fue uno de los elementos básicos de los monumentos funerarios. En épocas posteriores se generalizó su empleo en la construcción y, aprovechando las cualidades naturales de las rocas ornamentales, en la realización de esculturas y como revestimiento para embellecer suelos y paramentos.

El mármol de Macael ha llamado la atención desde tiempos remotos por la blancura de algunas de sus variedades. El indicio más lejano de su uso, y por tanto de actividad en las canteras, lo sitúan algunos especialistas en un sarcófago antropoide de la época fenicia (siglo $V$ antes de Cristo) encontrado en Cádiz (Grima Cervantes, 1994: 33). Pero es a partir de la dominación romana cuando su empleo adquiere mayor auge. El descubrimiento de objetos elabora- 
dos con mármol procedente de las canteras de Macael es abundante. Aunque el debate acerca del origen del mármol de algunas destacadas muestras se mantiene abierto, bastantes especialistas lo citan como uno de los materiales empleados en Mérida (Chávez Álvarez, M.E. et al., 2002: 143). Piezas de Itálica estudiadas por Cantó (1977-1978: 180) permiten asegurar que las canteras de Macael estuvieron en funcionamiento al menos desde Vespasiano (segunda mitad del siglo I) a los Severos (final del primer tercio del siglo III). Esta tesis se ve reforzada por la aparición de lápidas y esculturas de esa misma época en entornos cercanos a las canteras (Cara Barrionuevo and Rodríguez López, 1992: 401).

Los árabes con sus construcciones impulsaron la actividad y crearon una incipiente industria que abarca desde el siglo $X$ al XV. Los ejemplos más destacados son Medina-Azahara, en la que el mármol embelleció solerías, baños y capiteles (Pastor Medina, 1990: 65), y la Alhambra de Granada. En esta última, sobresale el Patio de los Leones, en el que columnas y capiteles, fuente y esculturas son de mármol blanco de Macael (Malpica Cuello, 2002: 224); en 2012, para que el patio luciera su aspecto original, se pavimentó con losas de ese mismo material.

Tras la toma de Granada, los Reyes Católicos, con el fin de ennoblecer y poblar Baza, anexionaron a esta ciudad varias villas, entre las que se encontraba Macael. El 20 de noviembre de 1501 se confirmó la cesión por Real Cédula dada en Écija; desde ese momento, los vecinos y moradores de Baza pueden "gozar, cortar y cazar en los términos comunes de dichas villas y lugares, y los de dichas villas y lugares en los términos comunes de la dicha ciudad de Baza, de manera que todo sea un cuerpo y la dicha ciudad de Baza sea la cabeza" (Magaña Visbal, 1978: I, 395).

La dependencia de Baza no cambió el estatus de los montes de Macael, que siguieron siendo comunales, pero afectó de manera sustancial a su uso, pues -con palabras de Magaña Visbal (1978: I, 397)aquella ciudad "entró inmediatamente a gozar de la posesión de las citadas villas, haciendo ordenanzas para el régimen y gobierno de ellas y sus términos, guarda de sus campos y demás cosas tocantes al buen orden y administración de justicia, dando las reglas que debían observarse en la corta de sus montes, imponiendo penas a los contraventores, prohibiendo la entrada de ganados forasteros sin las debidas licencias; todos aquellos actos, en fin, que suponen posesión y dominio". Y así, concedió, a veces con prepotencia, permisos para el aprovechamiento de su riqueza (pasto, leña y mármol), en ocasiones lesionando los derechos de los vecinos de Macael. No faltan reclamaciones de particulares y del concejo de esta villa presentadas ante las autoridades de Baza y la Real Chancillería de Granada pidiendo justicia ante algunos de esos abusos (Pastor Medina, 1990: 72).

En los primeros años del siglo XVI el mármol se extraía libremente por vecinos y forasteros. Así se deduce de la ordenanza promulgada por el concejo de Baza en octubre de 1518, que - con el pretexto de que la ciudad tiene pocos propios y que cuenta con la "provisión de Sus Altezas para buscar donde se pueda hallar alguna renta o provecho" y acogiéndose a que el mármol se está extrayendo con mucho desorden- prohíbe extraer piedra a los que no sean vecinos de la ciudad si antes no tienen licencia, que obliga a pagar "treinta y cuatro maravedíes por cada carretada de una yunta. Y si fuese de más yuntas la carretada, por cada yunta un real. Y si fuese por cargas de bestias paguen por cada carga diez maravedís" (Ordenanza de 29 de octubre de 1518). Esta disposición, que atentaba contra la naturaleza comunal de las canteras y apartaba a Macael de su aprovechamiento, fue suspendida en mayo del año siguiente y acabó derogándose definitivamente en 1523.

Con el avanzar del siglo la extracción continúa. Aunque sujeta a los altibajos propios de la actividad constructiva, la petición de mármol para embellecer palacios y casas señoriales no cesa; cuando el destino así lo aconseja, como es el caso de Sevilla, el material se transporta a la playa de Vera donde se embarca (Otte, 2008: 185-186). Diversas fuentes hablan del trabajo de los canteros durante esos años; algunos eran de fuera - artistas que "vivían a caballo entre la cantera y las ciudades donde trabajaban" (Castillo Fernández, 1999: 52-53) - y otros repobladores, entre los que los abandonos no fueron una excepción por las duras condiciones del lugar (Castillo Fernández, 1999: 106-109).

\section{Las canteras "siempre han sido libres y comunes a todos"}

Las benévolas condiciones que los Reyes Católicos dictaron para los vencidos tras la conquista se fueron endureciendo en los años sucesivos, provocando diversos levantamientos que tuvieron su culmen tras la Pragmática dictada por Felipe II en 1567- en la rebelión general de los moriscos de 1568. Derrotados en 1571 por Juan de Austria, los rebeldes fueron expulsados. Para resolver los graves problemas derivados de la despoblación, Felipe II dictó ese mismo año una provisión para el apeo y la población de las haciendas que habían pertenecido a los moriscos. Macael desde la rebelión hasta 1573, año en el que se 
realizó el apeo, quedó prácticamente deshabitada. Cuando se produjo el levantamiento vivían en el lugar alrededor de 80 familias y tras el repoblamiento se asentaron 22, las determinadas en la Provisión (Pastor Medina, 1990: 49).

Lo anterior ayuda a entender porqué en el apeo de la villa no se da a las canteras especial relevancia. En las páginas iniciales del libro, al describir los rasgos generales del término, se citan límites y extensión, ejidos y dehesas, fuentes y acequias, molinos, almazaras y hornos, tierras de riego y de secano, olivos y moreras..., pero no se hace mención alguna de las canteras de mármol. Tampoco se refieren oficios relacionados con ellas entre las ocupaciones de los pobladores.

El 19 de agosto se apearon varios secanos. De algunos se refiere que lindan con las canteras de mármol o con las canteras de Filabres; es en el llamado pago de Azlar en el que, según recoge el libro,
"Apearonse las canteras que son de mármol y están en el dicho pago, término del lugar de Macael, a media legua del poco más o menos, que se llaman las canteras de Filabres, y se declaró por el seyse que siempre han sido libres y comunes a todos generalmente, sin que en ello haya visto ni entendido que haya habido contradicción" (Libro de Apeo de Macael, 1573). Es una referencia tan breve como importante. En estas pocas líneas se ha apoyado la secular lucha que ha mantenido el pueblo de Macael para defender la propiedad de las canteras, tanto contra las pretensiones de particulares como de la administración. "Libres y comunes a todos" quiere decir, según apunta González Alcantud (1990: 17-18), que el cabildo no tenía autoridad sobre ellas, lo que se ajusta a la manera de organizarse la taha musulmana. Macael, tras la conquista, al tiempo que incorpora la estructura jurídica castellana, mantuvo algunas costumbres en cuanto a la propiedad, uso y disfrute de

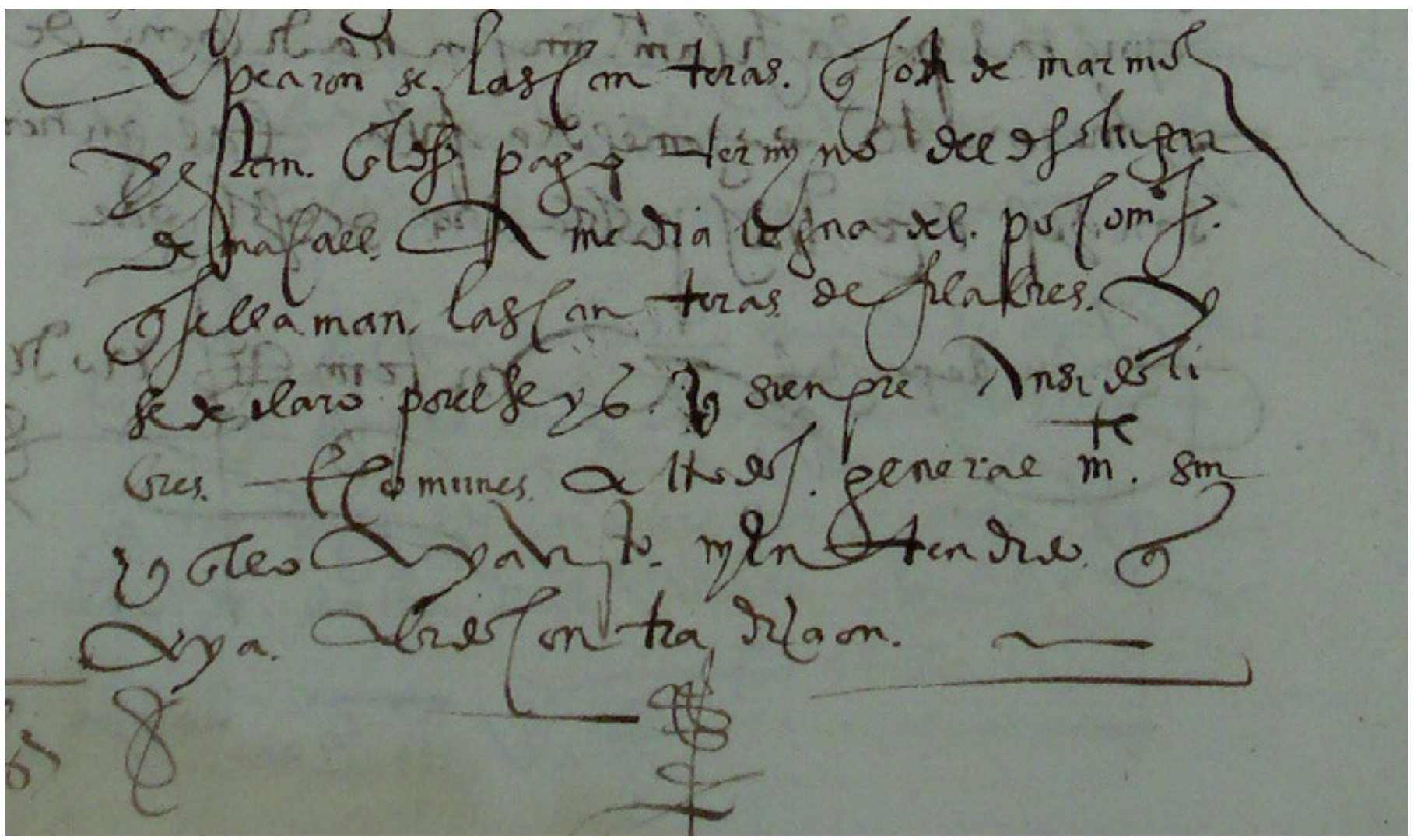

Figura 1. Fragmento del Libro de Apeo de la villa de Macael (1573) que recoge el apeo de las canteras: "Apearonse las canteras que son de mármol y están en el dicho pago, término del lugar de Macael, a media legua del poco más o menos, que se llaman las canteras de Filabres, y se declaró por el seyse que siempre han sido libres y comunes a todos generalmente, sin que en ello haya visto ni entendido que haya habido contradicción". Fuente: Libro de Apeo de la villa de Macael. Archivo de la Real Chancillería de Granada.

Figure 1. Fragment of the Register Book of Macael village (1573), which describes the demarcation of the quarries: "The marble quarries were demarcated in that land, situated half a league away from Macael, more or less. The quarries are known as "those from Filabres." It has been declared by the "seyse" - the legal of the place - that they have always been free of any charge and have generally belonged to the whole community with no distinction, assuring that he has never appreciated a minimum contradiction regarding this statement." 
las tierras comunales: al margen del consejo, según la tradición mora, y usufructuadas libremente y/o subastadas o sorteadas, en la tradición mixta musulmana-castellana. Lo cual no impide que durante la época morisca los bienes comunales puedan pasar a privados por su ocupación y utilización ininterrumpida durante un tiempo, e incluso venderse mientras se mantenía esa situación, suponiendo su abandono el fin de cualquier derecho (Grima Cervantes, 1993: 295).

Cuando tiempo después, en 1751, se llevó a cabo el catastro de Ensenada, las respuestas de los principales de la villa de Macael a las preguntas del interrogatorio vuelven a sorprender. Acerca de "si hay algunas Minas, Salinas, Molinos Harineros, ù de Papel, Batanes, ù otros Artefactos en el Termino, distinguiendo de què Metales, y de què uso...", responden que "tan solo ay tres molinos Arineros y uno de Azeite... y que de lo demás que concierne a la pregunta, no ay en esta villa ni en su término cosa alguna". Al tratar de las ocupaciones de los habitantes no mencionan ninguna ligada con la actividad extractiva, a pesar de que la profesión de cantero es una de las que se citan en la pregunta. Llegado el momento de responder "qué Propios tiene el Comun, y à què asciende su producto al año" y si "el Común disfruta de algún Arbitrio", contestan que "no tiene propios algunos" y, como consecuencia, la villa no disfruta tampoco de arbitrios (Catastro de Ensenada, 1751, Interrogatorio, Preguntas 17, 23, 24 y 33).

Las respuestas pueden llevar a pensar en un ocultamiento de la actividad extractiva por motivos fiscales, que era uno de los objetivos del catastro. Pero también se pueden explicar si consideramos que las canteras en esa época solían tener un funcionamiento intermitente, en función de los encargos que recibían y de la atención del campo; era habitual que en determinadas temporadas del año el trabajo en las canteras se compatibilizara con las labores agrícolas, o incluso se abandonara. Lo que está claro es que en Macael esos años hubo actividad y, en algunos casos, ligada a la corona. Así como a finales del XVI se solicitó mármol para el monasterio de El Escorial, ahora, coincidiendo con la elaboración del catastro, se demanda para el palacio Real de Madrid y el de la Granja de san Ildefonso.

\section{Siglo XIX. De bienes comunales a propios}

El siglo XIX, con la llegada al poder de gobiernos liberales, trajo consigo profundos cambios legislativos $y$ sociales que tuvieron importantes repercusiones en la vida del país. El nuevo ordenamiento jurídico y administrativo buscaba poner las bases para pasar de un esquema de funcionamiento propio de la sociedad preindustrial a otro más acorde con los tiempos que se avecinaban; una de las reformas determinantes fue el impulso que recibieron las instituciones, y entre ellas los ayuntamientos (Aguilera Klink, 1987: 123). En el ámbito de nuestro interés, en 1811 vio la luz un decreto (de fecha 6 de agosto) por el que se incorporaban a la nación los señoríos jurisdiccionales, y poco después las Cortes Generales aprobaron -con el fin de fomentar la agricultura y la industria, y de aliviar las necesidades públicas - reducir a propiedad particular "todos los terrenos baldíos ó realengos, y de propios y arbitrios..., excepto los exidos necesarios á los pueblos", recibiendo las diputaciones el encargo de llevar a cabo la resolución (decreto de 4 de enero de 1813).

Estas disposiciones no afectaron al devenir de Macael. El hecho de que en 1819 se celebrara un cabildo general y abierto - se convoca a los vecinos para tratar asuntos de su interés - en el que se habla de que "no hay ningunos fondos de propios, ni fincas agregadas a ellos que puedan producirlos, ni débitos de ninguna persona en favor de dichos propios ni tampoco ningunos arbitrios de que poder echar mano para cubrir las cargas o gastos que se originan ordinariamente todos los años" (Acta Municipal, 7 de marzo de 1819), confirma que las canteras en ese momento pertenecían al común y no generaban ningún ingreso.

A pesar de las muy diversas situaciones por las que pasó la España del siglo XIX, las constantes necesidades financieras de la administración pública y los beneficios que algunos sectores sociales vislumbraron que les podía reportar, hicieron que una vez iniciado el proceso desamortizador ya no se detuviera. $Y$ así, impulsando el proceso iniciado en 1813, la Real Orden de 24 de agosto de 1834 establece las reglas para que "sea uniforme el método que se siga en las enajenaciones de predios rústicos y urbanos, pertenecientes á los propios de los pueblos, y facilitar la reducción de estos bienes á dominio particular", dejando a los ayuntamientos encargados de formar "los oportunos expedientes para la subasta de la finca ó fincas de los propios que convenga enajenar", aunque sometidos a la aprobación final del gobernador civil de la provincia.

Durante la segunda mitad de la década de los treinta, la nueva organización administrativa puso fin a la dependencia de Baza y, tras un paréntesis de más de trescientos treinta años, Macael recuperó el control de sus montes. El cambio del marco jurídico abrió la puerta para restringir el libre acceso y comenzar a exigir un arbitrio a quienes se concedía licencia para extraer el mineral. Los montes pasaron a ser bienes 
de propios, aunque el Ayuntamiento, ante las instancias superiores, siguió defendiendo con determinación su condición de comunales para impedir su venta, en un doble juego que se prolongó todo el siglo. Con el fin de sacar provecho a la nueva situación, el 7 de julio de 1841 se publican en el Boletín Oficial de la Provincia las condiciones para la subasta por cinco años de la cantera del Pozo, y se convoca a quienes quieran mejorar las condiciones ofrecidas por Antonio Canals y Diego Giménez para el aprovechamiento por nueve años de las canteras Virgen del Rosario y San Pedro. Las actas municipales de los días 14 y 18 de julio dan fe de la adjudicación de la cantera del Pozo, en subasta celebrada el día 11, a “D. Manuel Moreno, vecino de Barcelona y residente en Fines" por la cantidad estipulada "en favor de los Propios del corriente año".

En 1851 una comisión parlamentaria envió un cuestionario a los ayuntamientos en el que, junto a preguntas acerca del origen, cuantificación y funcionalidad de los bienes de propios, pide la opinión municipal sobre su posible enajenación para financiar inversiones públicas. El estado ofrece una rentabilidad por el resultado de esas desamortizaciones (el $6 \%)$ para compensar a los municipios por los ingresos que esos bienes les estuvieran reportando. El rechazo fue la respuesta más común a esta pretensión institucional de convertir parte del capital territorial municipal en capital financiero (Fernández Carrión, 1993: 40-47). Algunos municipios optaron por el silencio, entre ellos el de Macael, que, con independencia de otras consideraciones, no tenía ningún interés en que cambiara el estado de las cosas (González Alcantud, 1990: 21).

Las disposiciones de la primera mitad del siglo $\mathrm{XIX}$, al centrar su atención en la enajenación de los bienes de propios, permitieron una mejor defensa de las canteras; pero en 1855 la ley Madoz cambió la situación y radicalizó el proceso. Esta ley, en su artículo primero, declara "en estado de venta" todos los predios rústicos y urbanos, entre otros los pertenecientes a "los propios y comunes de los pueblos", exceptuando los terrenos que en esos momentos son de "aprovechamiento comun, prévia declaracion de serlo, hecha por el Gobierno, oyendo al Ayuntamiento y la Diputación provincial respectivos" (artículo $2^{\circ}$, noveno). La exigencia de la declaración previa de los bienes de aprovechamiento común, como requisito para no ser vendidos, fue una de las mayores preocupaciones de los mandatarios de Macael durante el siguiente medio siglo.

En junio de 1856, obligado por una Real Orden de 6 de marzo $-y$ excusándose por no haberlo hecho antes, pues entendía que se excluirían de la venta sin gestión alguna, por ser notoria su necesidad para el pueblo-, el Ayuntamiento solicita al Gobierno que los montes "se declaren de aprovechamiento común del vecindario..., exceptuándose de la enajenación prevista", aduciendo "que no solo así viene sucediendo desde el primer momento de su existencia y está autorizada por el libro de Población, sino que no es posible otra cosa" por las particularidades del municipio (Acta Municipal, 15 de junio de 1856). Apenas ha pasado un año desde esa petición, cuando el Gobernador Civil insta a la corporación municipal a incluir "Ias canteras de mármol que están aprovechando el común de los vecinos de esta villa" en la relación de bienes que se le ha pedido, recordándole que la omisión es constitutiva de delito. Tras estudiar la normativa en vigor e invocando el libro de Apeo, la corporación contesta - no sin cierto atrevimientoque no hizo relaciones "de unas fincas que en manera alguna han pertenecido a Propios ni al Estado, al menos en esa creencia viven y están dispuestos en todas ocasiones a sostener estos sagrados derechos" (Acta Municipal, 27 de septiembre de 1857).

Por fin, y por un camino indirecto - la demanda de un particular-, se reconoce la exclusión de venta de los montes. El 10 de marzo de 1860 el Gobierno Civil traslada al Ayuntamiento la Real Orden con la noticia: “La Junta Superior de Ventas, en sesión de 29 de febrero de 1860, con el dictamen de la Asesoría General del Ministerio de Hacienda y de la Dirección General de Propiedades y Derechos del Estado, se sirvió declarar improcedente la demanda hecha por el investigador que fue de esta provincia don Francisco Camacho de unas canteras de mármol, de este término municipal en atención a que declaradas de aprovechamiento común por el artículo $3^{\circ}$ de la Ley de Minas de 11 de abril de 1849 y el 17 del Reglamento de 31 de Julio de dicho año para su ejecución, se hayan expresa y absolutamente comprendidas en el caso $9^{\circ}$ del artículo $2^{\circ}$ de la Ley de $1^{\circ}$ de mayo de 1855 , no habiendo habido por consiguiente obligación de relacionarlas" (Actas Municipales, 5 de septiembre de 1897 y 30 de enero de 1898).

Mientras tanto, el Ayuntamiento sigue obteniendo ingresos por extraer mármol. En julio de 1865, para evitar que no paguen arbitrio los que sacan el mineral de la sierra por los caminos que conducen a fábricas situadas en otros municipios (Fines, Cantoria, Olula del Río y Purchena), se nombra a "una persona que diariamente suba a las canteras para ver y presenciar la extracción que se haga, para tomar razón de ello y que se paguen el número de pies que extraigan" (Acta Municipal, 23 de julio de 1865). 
Las subastas convocadas para extraer mármol en determinadas zonas de la sierra no impiden la actividad de otros canteros en otras zonas, siempre contando con el oportuno permiso. Así lo afirma el Alcalde en una carta al Gobernador Civil en septiembre de 1903, en la que escribe, al darle cuenta del fin de una huelga, que "Ios que no quisieran trabajar a jornal podían hacerlo por su cuenta propia como lo hacen en todo tiempo, por pertenecer las canteras al común de vecinos" (Archivo Histórico Provincial de Almería, Interior, caja 4929, legajo 30).

Cuando el siglo se acerca a su fin, se siguen dando pasos para la aplicación de la ley Madoz. Tras diversas normativas complementarias $-y$, en ocasiones, confusas $-y$ repetidas prórrogas para que los pueblos presenten las relaciones de bienes que les son imprescindibles, en 1897, por Real Decreto de 16 de noviembre, se concede un nuevo plazo de tres meses para solicitar "que se exceptúen de la venta montes y terrenos de su pertenencia con destino al aprovechamiento común ó al pasto de sus ganados de labor". Han pasado casi cuarenta años desde que el Gobierno Civil comunicara que no es preciso relacionar las canteras, y quizás por ello, y con el fin de recordarlo con ocasión de este decreto, la corporación municipal ve conveniente insistir en el asunto, invocando la Real Orden de marzo de 1860 que lo determinó (Acta Municipal, 30 de enero de 1898).

Todos estos tiras y aflojas dieron su fruto. Según Fernández Carrión (1993: 144), Macael fue uno de los pocos municipios, de entre los 21 del partido judicial de Purchena, en los que no se desamortizaron bienes durante la segunda mitad del XIX.

Con todo, el estado sigue buscando ingresos, y en mayo de 1905 la Administración Provincial de Hacienda vuelve a pedir al Ayuntamiento que explique los motivos por los que solicita la excepción de venta de los montes. En esta ocasión, reconociendo abiertamente los bienes como de propios, la corporación municipal invoca el "concepto de dehesa boyal con arreglo al artículo $3^{\circ}$ de la Ley del 8 de mayo de 1888 , por haberse declarado bienes de propios los comunales de esta localidad, producir pastos y no tener exceptuados terrenos de ninguna especie", $y$, acogiéndose a los beneficios del artículo 30 de la Ley de 26 de junio de 1898, se compromete a "satisfacer al Estado el veinte por ciento de la tasación y los gastos preliminares de la subasta" (Acta Municipal, 13 de mayo de 1905). Pocos días después, el 2 de junio, la Administración de Hacienda pide al Ayuntamiento la documentación necesaria para proceder a la tramitación del expediente en las condiciones solicitadas (Acta Municipal, 10 de junio de 1905).

Tampoco tuvo apenas influencia en las labores de extracción del mármol la abundante normativa minera que trajo consigo el siglo XIX, pues tenía en su punto de mira otras sustancias. Tras 240 años en los que la actividad minera se rigió por las ordenanzas dictadas en 1584 por Felipe II, complementadas a lo largo de ese prolongado periodo con diversas disposiciones que iban cubriendo sus lagunas, el cambio político y la fuerte expansión minera del XIX exigieron que se actualizara la legislación. El 4 de julio de 1825 ve la luz un Real Decreto que establece que todos los yacimientos pertenecen a la Corona, asienta la libertad de explotación del subsuelo y regula la concesión de explotaciones de minas mediante un procedimiento administrativo; pero contempla, en su artículo segundo, un trato particular para "las producciones minerales de naturaleza terrosa, como son las piedras silíceas y las de construcción, las arenas, las tierras arcillosas y magnesianas, y las tierras calizas de toda especie", que "continuarán como hasta ahora de aprovechamiento común o particular, según los terrenos en que se encuentren, sin necesidad de concesión".

Las leyes de Minas de 1849 y 1859 no alteran ese criterio; la de 1859, en su artículo tercero, señala que estas sustancias "no quedan sujetas a las formalidades ni cargas de la presente ley", únicamente "estarán bajo la vigilancia de la Administración en lo relativo a la policía y seguridad de las labores". En igual dirección apuntan las reformas aprobadas en marzo de 1868 para incorporarlas a la Ley de Minas. La ley de bases de diciembre de este mismo año divide las sustancias en tres secciones, en la primera se encuentran “las producciones minerales de naturaleza terrosa, las piedras silíceas, las pizarras, areniscas o asperones, granitos, basaltos, tierras y piedras calizas, el yeso, las arenas, las margas, las tierras arcillosas, $y$, en general, todos los materiales de construcción cuyo conjunto forma las canteras", y establece que estas sustancias "son de aprovechamiento común cuando se hallan en terrenos de dominio público. Cuando estén en terrenos de propiedad privada, el Estado, confirmando el art. $3 .^{\circ}$ de la ley vigente de minas, cede dichas sustancias al dueño de la superficie, quien podrá considerarlas como propiedad suya, y utilizarlas en la forma y tiempo que estime oportunos, sin que quede sometido a las formalidades y cargas del presente decreto. Estas explotaciones solo estarán sujetas a la intervención administrativa en lo que se refiere a la seguridad de las labores, según determine el reglamento de inspección y policía mineras" (artículo $7^{\circ}$ ). Aunque la ley de bases distingue entre el suelo y el subsuelo de un terreno y los derechos sobre cada uno, esta diferencia queda difuminada para las sustancias de la sección primera. 


\section{Intentos de particulares para acceder a la propiedad}

A caballo entre la segunda y la tercera década del siglo $X X$ tiene lugar un acontecimiento cuyas consecuencias van a marcar la vida de Macael durante años. El pésimo estado de las finanzas municipales, que exigía una solución urgente, y la insistencia de algunos empresarios para alargar los plazos de las concesiones, alegando que esto mejoraría el orden en el trabajo y aumentaría el rendimiento de las explotaciones, fueron las principales razones para convocar una subasta con unas condiciones excepcionales: extraer cuatro mil metros cúbicos de mármol anuales durante veinte años. La iniciativa, al parecer, partía de Antonio Ortiz que era el empresario más importante del momento y contaba con mucha influencia en el cabildo (González Alcantud, 1990: 71).

A mediados de 1919 el Ayuntamiento aprobó el pliego de condiciones de la subasta (Acta Municipal, 4 de mayo de 1919), que por disposición de la Delegación de Hacienda de la Provincia quedó convocada para el 2 de marzo de 1920 (Boletín Oficial de la Provincia del 5 de febrero). El 27 de abril la Dirección General de Propiedades e Impuestos adjudicó la subasta a José Martínez Cruz, que había ofrecido 55.025 pesetas anuales, y el 8 de mayo le fueron entregadas oficialmente las canteras. Por las peculiaridades del proceso y los conflictos que originó, es conocido desde entonces como el "Rematante" (con mayúscula).

Derrotado $-y$, es de suponer, que muy disgustado-, Antonio Ortiz volvió a la alcaldía en abril de ese mismo año y desde ella, "en defensa de los intereses del vecindario", maldice la recién celebrada subasta que puede conducir al "agotamiento de los criaderos de mármoles" (Acta Municipal, 9 de mayo de 1920). Una de las causas de su enojo eran los terrenos adjudicados al Rematante, que fueron desde el principio una constante fuente de conflictos, pues - según el parecer de la Comisión de Montes del Ayuntamiento- el Ingeniero Jefe de la Región le entregó más hectáreas de las 27 señaladas en el pliego de condiciones, incluyendo canteras y propiedades que algunos - entre ellos Antonio Ortiz- reclamaban como propias. Las denuncias obligaron a realizar costosos trabajos de deslindes (Acta Municipal, 7 y 8 de mayo de 1921), y desembocaron en la fijación de una "franja prohibitiva" para la extracción del mármol, que obligó a paralizar muchas canteras y fue una nueva causa de demandas, tanto por parte del Ayuntamiento como de los afectados, pues dejó "en la más completa miseria infinidad de familias" que ganaban en ellas su sustento (Acta Municipal, 19 de junio de 1921).
Coincidiendo con la polémica por los deslindes, Antonio Ortiz reclamó la propiedad de unas canteras que su familia explotaba desde 1887. Como la corporación municipal -que está a su favor - no puede aportar documentos que demuestren la ocupación de los treinta años que exige la ley, emite un certificado indicando que se trata de un hecho "público y notorio" (Acta Municipal, 22 de mayo de 1921). En agosto de 1922 la Dirección General de Contribuciones e Impuestos reconoce el derecho solicitado y, siguiendo órdenes de la Delegación de Hacienda de Almería, en septiembre el Ayuntamiento le entrega los terrenos. Pero en la historia de esa larga e ininterrumpida ocupación que Antonio Ortiz alega, hay un antecedente de no poca trascendencia: en febrero de 1899, veintidós años antes de la propiedad que ahora demanda, obtuvo el derecho de explotación a perpetuidad de esas canteras siendo él mismo el alcalde de la localidad (Acta Municipal, 22 de octubre de 1926).

En similar situación a los Ortiz se encontraban otros empresarios pero no tuvieron la misma suerte $y$, al no poder probar los treinta años de ocupación, perdieron las zonas que estaban explotando que pasaron a formar parte de los terrenos del Rematante (Ramos Sánchez and Rodríguez Padilla, 2010: 38).

En el proceso por los deslindes a veces se vio favorecida una parte y en otras ocasiones la otra. Si en 1924 el Ministerio de Hacienda da la razón al Rematante, unos años más tarde, en 1927, el Tribunal Supremo dicta sentencia en su contra. Señala este tribunal que, por tratarse del deslinde de un monte público, sólo pueden intervenir en el asunto la entidad propietaria (el Ayuntamiento) y los propietarios particulares colindantes o enclavados en el monte, y a ninguno de los dos grupos pertenece Martínez Cruz, por lo que no le corresponde ninguna acción en defensa de un dominio del que carece. En noviembre de 1928 se confirma la sentencia que reconoce la propiedad de las canteras particulares. Unos meses antes, en julio, había fallecido Antonio Ortiz.

Entre tanto, el Ayuntamiento sigue gestionando los montes como bienes de propios, mientras de palabra los califica como comunales o bienes del pueblo. Por ejemplo, en mayo de 1920, tras recibir del Rematante el dinero de la subasta, ingresa "en la Hacienda el 20 por \% de propios que le corresponde" (Acta Municipal, 9 de mayo de 1920); y unos años más tarde, el entonces alcalde Francisco Martínez García, tratando de la propiedad privada de algunas canteras, apunta que "todos sabemos que los lugares donde se hayan enclavadas las canteras, pertenecen y pertenecieron al Comunal" (Acta Municipal, 22 de octubre de 1926). Muy probablemente en el fondo de este doble lenguaje se entremezclan el desconoci- 
miento de las características distintivas de los bienes de propios y comunales, y la convicción de que los montes y el mármol son del pueblo, con independencia de que sea preciso solicitar permiso y pagar para extraerlo.

Recién estrenada la II República, Antonio Valdés Campillo, alcalde en ese momento, ve una nueva oportunidad para recuperar las propiedades perdidas por el municipio, y presenta un escrito "firmado por todos los vecinos de este pueblo en súplica para que sea elevado al Excmo. Sr. Presidente provisional de la República pidiendo, por ser de justicia, que se ordene la rectificación del deslinde de los montes comunales del pueblo, o sea que los montes donde radican los mármoles vengan a ser, como siempre fueron, de los vecinos de esta villa" (Acta Municipal, 2 de mayo de 1931).

A finales de 1931 los acontecimientos se precipitan. El 21 de noviembre se presenta una denuncia contra el Rematante por incumplir algunas de las condiciones de la subasta. La celeridad con la que actuó el Ayuntamiento - que en cinco días acuerda "la nulidad total de la subasta de las canteras de mármol de estos montes públicos al Rematante Don José Martínez Cruz" (Acta Municipal, 26 de noviembre de 1931) - hace pensar que estaba al tanto de lo que iba a ocurrir. Tras asegurarse de que tenía las competencias oportunas (Oficio del Gobierno Civil de la provincia al Alcalde de Macael de fecha 5 de enero de 1932, número 14. Archivo municipal de Macael), en las sesiones del 7 de enero y del 12 de febrero de 1932 la corporación municipal hace firme el acuerdo de rescisión del contrato con el Rematante, fundamentándolo en que "no ha respetado en nada el pliego de condiciones muy particularmente la clausula $3^{\text {a }}$ de este", que trata del vertido de escombros sobre bancos de mármol sin explotar (Acta Municipal, 7 de enero de 1932). El 17 de febrero Martínez Cruz firma

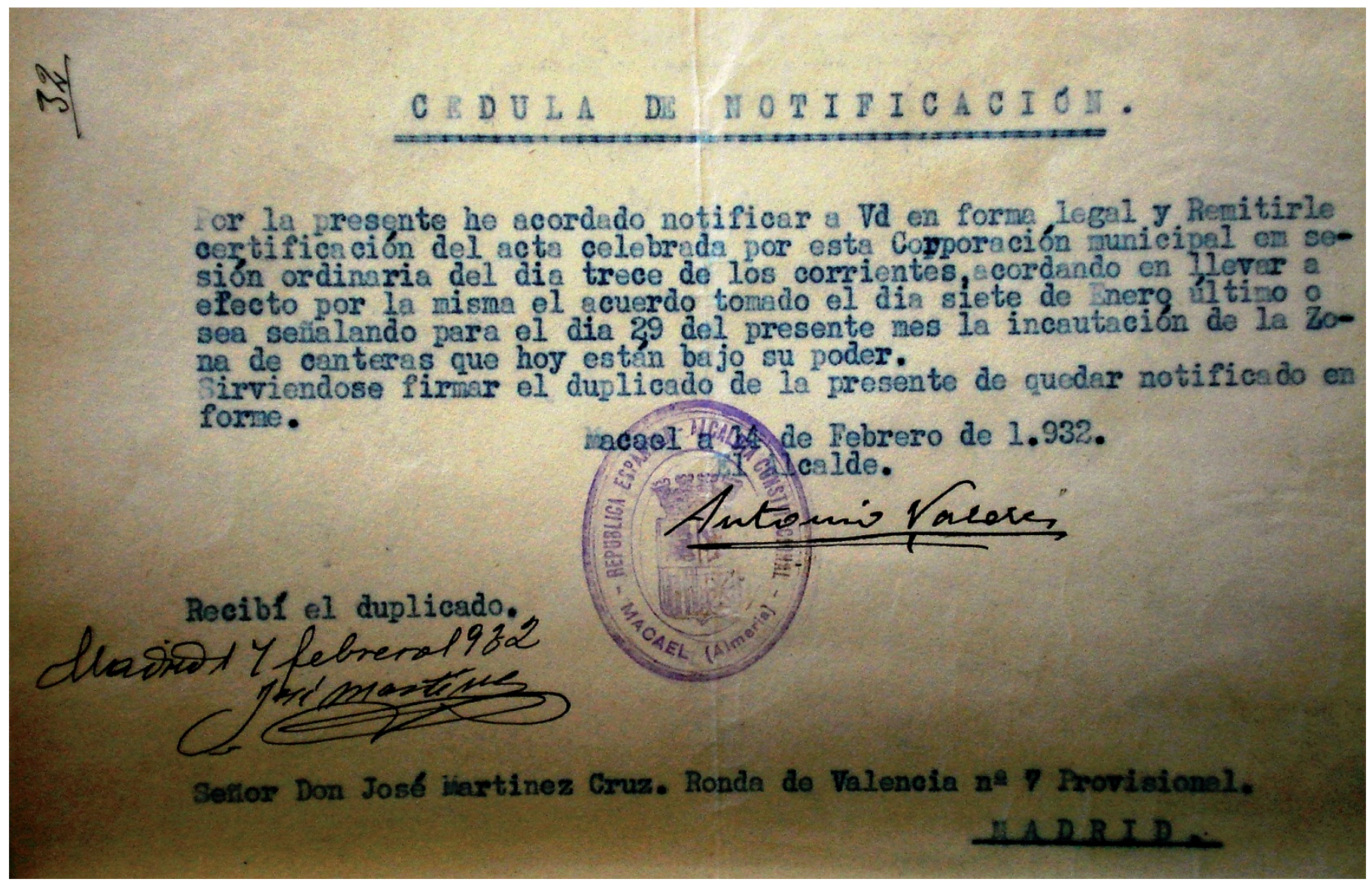

Figura 2. Cédula de Notificación del Ayuntamiento de Macael a José Martínez Cruz, Rematante de la subasta de mármoles de 1920, comunicándole la rescisión del contrato y la incautación de las canteras. Fuente: Archivo Municipal de Macael.

Figure 2. Macael Town Council notifies José Martínez Cruz in 1920, marble auction bidder, the cancellation of the contract and the confiscation of the quarries. 
en Madrid la notificación que le comunica la decisión, y que fija el 29 de ese mismo mes como fecha de incautación de las canteras que hasta el momento estaban en su poder.

Tras el fallecimiento de Antonio Ortiz, la familia sigue defendiendo la propiedad de varias canteras. En 1934 Juan Rubio, yerno de Antonio y anterior defensor de los derechos municipales frente al Rematante, solicita no pagar canon por mármoles extraídos en terrenos que son suyos. El Ayuntamiento deniega la petición argumentando que las canteras están "dentro de los montes comunales del pueblo", cosa que no es preciso probar "puesto que viene en posesión tradicional y pacífica de ellos y de la explotación de sus canteras de mármoles desde tiempo inmemorial" (Acta Municipal, 23 de junio de 1934), lo que lleva a Rubio a elevar su reclamación a instancias superiores.

Pero no tardan en cambiar las tornas... y, con ellas, los intereses. Tras el triunfo del Frente Popular en febrero de 1936, Juan Rubio accede a la alcaldía y unos meses después su mujer, Clementina Ortiz, que era una de las herederas de las canteras cuya propiedad estaba en litigio, renuncia "para sí y para los suyos a cualquier derecho que pudiera tener en concepto de propietaria sobre explotación de canteras de mármol". El propio Rubio firma el documento, autorizando la renuncia de su esposa en beneficio del pueblo (Acta Municipal, 27 de junio de 1936).

Antes de terminar el año una nueva corporación más radical, presidida por Antonio Martínez Tijeras, cita a los demás herederos (Acta Municipal, 26 de diciembre de 1936), que siguiendo los pasos que seis meses antes había dado Clementina - aunque es de suponer, a pesar del tono conciliador del acta de la sesión, que con no poca presión por la situación política-, "manifiestan libre y espontáneamente" que "no reconocen propiedad alguna sobre ninguno de los yacimientos de mármoles, por lo que en este acto dejan bien sentado que en el supuesto de existir, hacen dejación de todo derecho por reconocer la legitimidad del pueblo" (Acta Municipal, 28 de diciembre de 1936).

\section{Últimos pleitos tras la Guerra Civil. Entre la justicia y la política}

Terminada la guerra civil vuelven a tomar vida los litigios. Los que se vieron privados de sus derechos durante la república esperaban alcanzar el favor de los nuevos gobernantes, pero nada más lejos de la realidad. José Martínez Cruz, el Rematante, solicita que le restituyan los derechos que adquirió al ganar la subasta de 1920 y que quedaron interrumpidos por las decisiones del Ayuntamiento de inicios de 1932. El Tribunal Supremo falló a su favor en noviembre de 1942; en enero de 1943 el Ayuntamiento acató la sentencia y le entregó las canteras, pero pocos días después se retractó. Las razones que dio para justificar este cambio de decisión - en el que el Gobernador Civil jugó un papel determinante- fueron las "torcidas interpretaciones de carácter legal" que se produjeron en el trámite de cumplimiento de la subasta, lo que aconsejaba "someter a estudio la circunstancia resolutoria de competencia de este Ayuntamiento a la deliberación de ulteriores momentos y superiores juicios, en atención a la importancia que entraña el problema" (Acta Municipal, 11 de febrero de 1943), lo que suponía un dilata sine die.

Martínez Cruz, con el favor de los tribunales, siguió insistiendo, pero el Ayuntamiento -siempre con el firme apoyo del Gobierno Civil, que en muchos momentos llevó la iniciativa- ya no cedió. Una muestra de ese respaldo es el oficio enviado a Macael en mayo de 1943, que trascribe otro del Ministro de la Gobernación al propio Gobernador Civil instándole a ordenar al Ayuntamiento que "se aplace toda posesión de las canteras y terrenos al Martínez Cruz, hasta que se resuelva por quien corresponda el problema de la posible inejecución de la sentencia del Tribunal Supremo" (Oficio del Gobierno Civil de la Provincia de fecha 21 de mayo de 1943, número 207. Archivo Municipal de Macael). El Ayuntamiento - no tiene otra alternativa - actúa conforme se le ordena (Acta Municipal, 20 de junio de 1943) y la política, una vez más, gana la batalla a la justicia.

Por su parte, en marzo de 1943 la familia Ortiz, alegando que actuó forzada por la situación, reclama la propiedad de los parajes a los que renunció en 1936. El asunto acabó también en los tribunales y el pleito que resolvió el caso se cerró durante la segunda mitad de la década, siendo alcalde Maximiliano Martínez que defendió a ultranza la propiedad municipal y llegó a pedir una entrevista con el Jefe del Estado para exponerle el caso (Acta Municipal, 30 de enero de 1946, en González Alcantud, 1990: 105); en sus gestiones, como en el caso anterior, contó siempre con el respaldo del Gobernador Civil. Apoyándose en la reciente Ley de Minas de 1944, en deslindes aún discutidos, en la presentación de copias de documentos no autentificados y en "derechos cuyo origen más o menos remoto arranca con lamentable frecuencia de verdaderas usurpaciones y desmembraciones de terrenos pertenecientes a los montes comunales, conseguidos cuando menos por dejación o abandono de los encargados de la administración y custodia del patrimonio municipal" - palabras que traen a la memoria la mencionada con- 
cesión de explotación a perpetuidad de 1899 a Antonio Ortiz-, la Audiencia Territorial de Granada dictó sentencia contraria a las Ortiz en diciembre de 1947. El 21 de abril de 1948, con la publicación de la sentencia, el asuntó quedó cerrado.

\section{Situación actual}

La Ley de Minas de 1944 incluye al mármol entre los recursos de la sección A (Rocas), y establece, en el artículo cuarto, que los dueños de los terrenos en los que se encuentren las pueden aprovechar como de su propiedad o ceder su explotación a otros; cuando estén en terreno de dominio y uso público serán de aprovechamiento común, y para explotarlas es preciso el permiso de la autoridad correspondiente. EI Ayuntamiento de Macael, como propietario de los terrenos en los que se asientan las canteras y ajustándose a la Ley, otorga licencias para extraer el mármol y cualquier vecino puede tener una cantera con solo solicitar el oportuno permiso y abonar los derechos de aforo del material extraído. Pero el nuevo marco jurídico no logra atajar la mayor parte de los problemas que el sector arrastra desde antiguo (proliferación de permisos, reducido tamaño de las explotaciones, inadecuada ubicación de los estériles, falta de rigor en la fijación de límites, etc.) y las soluciones que desde diversas instancias se proponen durante las décadas de los cincuenta y los sesenta tienen escaso éxito.

La Ley de Minas de 1973, que sustituyó a la de 1944, fue la piedra angular del Plan Nacional de Minería, enmarcado dentro del II Plan de Desarrollo Económico y Social. Aunque siguiendo el texto de la ley las rocas ornamentales estarían incluidas entre los recursos de la sección A (yacimientos de valor escaso y comercialización de ámbito reducido), disposiciones posteriores determinaron su inclusión entre las sustancias de la $\mathrm{C}$, reservada a recursos no incluidos en las otras secciones; esta nueva clasificación supuso un cambio sustancial con respecto a la situación anterior. Como apunta Carbajo Josa (1994: 87), abrió la puerta a incentivos fiscales por el factor agotamiento y a la obtención de permisos de exploración e investigación y de concesiones de explotación; además, las sustancias de la sección $\mathrm{C}$ tienen implícita la consideración de utilidad pública, y el dominio público tiene más fuerza que en los recursos de las otras secciones al estar sometidas a concesión administrativa; una consecuencia de esto es que la propiedad del suelo y el derecho de aprovechamiento del recurso están desconectados, pudiendo ser ostentadas por personas físicas o jurídicas diferentes.
El Ayuntamiento de Macael vio en la nueva Ley la oportunidad para poner orden en las explotaciones y racionalizar la extracción. La particularidad de la zona requirió un tratamiento específico que, entre otros motivos, venía exigido por la nueva unidad introducida por la ley - la cuadrícula minera (unas 33 hectáreas) - y el establecimiento de que las concesiones de explotación se otorguen en cuadrículas mineras completas (artículo 62) y que éstas sean indivisibles (artículo 75). Aunque era una cuestión que afectaba más al arrendamiento de las concesiones que a las concesiones mismas, no se podía dejar de lado que en Macael, en esos momentos, había cuadrículas en las que convivían más de veinte canteras. Atendiendo a la situación de la zona, a sus peculiaridades y a razones históricas, se admitió lo que se podría denominar la "excepción de Macael", que aseguró a los explotadores arrendatarios los derechos adquiridos hasta el momento.

Fue también la ocasión para hacer un levantamiento planimétrico de la sierra y delimitar con exactitud el perímetro de cada cantera. Durante la primera mitad de 1976 se presentaron al Pleno del Ayuntamiento los planos con la delimitación y deslindes de 85 canteras (Actas Municipales de 8 de enero, 1 de junio y 6 de julio). Una vez aprobados, se entregaron 72 Licencias de Explotación a titulares que venían disfrutando de esta autorización desde antiguo (Acta Municipal, 23 de septiembre de 1976).

La Ley de 1973 permitió al Ayuntamiento consolidar los derechos sobre las canteras, tanto de las situadas en sus montes de propios como de otras ubicadas en otros municipios, y obtener la concesión directa para su explotación "por un período de 30 años, prorrogables por plazos iguales hasta un máximo de 90". Por otra parte, la ley permite al titular de una concesión de explotación trasmitir, arrendar o gravar sus derechos en todo o en parte, solicitando permiso a la autoridad concedente.

Los cambios derivados de la nueva legislación obligaron a revisar la relación entre el Ayuntamiento y los extractores, lo que se tradujo en la formalización en 1987 de un contrato de arrendamiento parcial de la concesión de explotación. Por ese contrato cada arrendatario adquiere la condición de explotador legal de la mina, al que el Ayuntamiento cede, además, el uso de los terrenos en los que se encuentra. Con el paso del tiempo el contrato fue objeto de modificaciones y mejoras.

Cuando terminaba el siglo, el Ayuntamiento de Macael era titular de siete concesiones para la extracción de mármol (Macael Norte, Macael Sur, Macael Este, Milagrosa, Segunda Milagrosa, San Andrés y Blanco Macael III) y de dos permisos de investigación 
(los dos con el nombre Blanco Macael). Las concesiones ocupan, con excepción de una pequeña superficie, todo el término municipal y se adentran en otros municipios: Laroya, Olula del Río, Purchena, Cantoria, Cóbdar, Chercos, Lijar, Albanchez.

Macael comparte su peculiar sistema para extraer el mármol con pocos lugares. Tiene cierta semejanza, por ejemplo, el caso de Pinoso (Alicante), municipio en el que se encuentra el monte Coto, propiedad del ayuntamiento, en cuyas canteras se extrae mármol crema marfil; aunque en este caso el producto obtenido está clasificado entre los recursos de la sección A de la ley de minas $y$, tema más secundario, el tamaño de la zona de explotación es sensiblemente inferior al de Macael.

A finales de 1988 se constituyó la Mancomunidad Intermunicipal de la Comarca del Mármol "Blanco de Macael", compuesta por Macael, Líjar, Laroya, Chercos y Purchena. Nace con los objetivos de reali- zar una gestión conjunta de las explotaciones mineras "Blanco Macael", y potenciar, desarrollar y fomentar la extracción, industrialización, comercialización y estudio del mármol de la zona. Al despedir el siglo la Mancomunidad tenía a su nombre seis concesiones de explotación (Rivamar I, II, III y IV, Las Águilas y Purchena), a las que habría que añadir la concesión Blanco Macael III y los dos permisos de investigación Blanco Macael, que solicitó el Ayuntamiento de Macael con el propósito de cedérselos a la Mancomunidad en el momento oportuno. No fue necesario mucho tiempo para comprobar que las esperanzas que se depositaron en la Mancomunidad eran excesivamente optimistas, propias de unos años de bonanza económica y fuerte demanda de mármol. Pronto quedó inactiva y todo lleva a pensar que acabará por disolverse; cuando ocurra, tanto las concesiones que están a su nombre, como muy probablemente las que el Ayuntamiento de Macael solicitó al

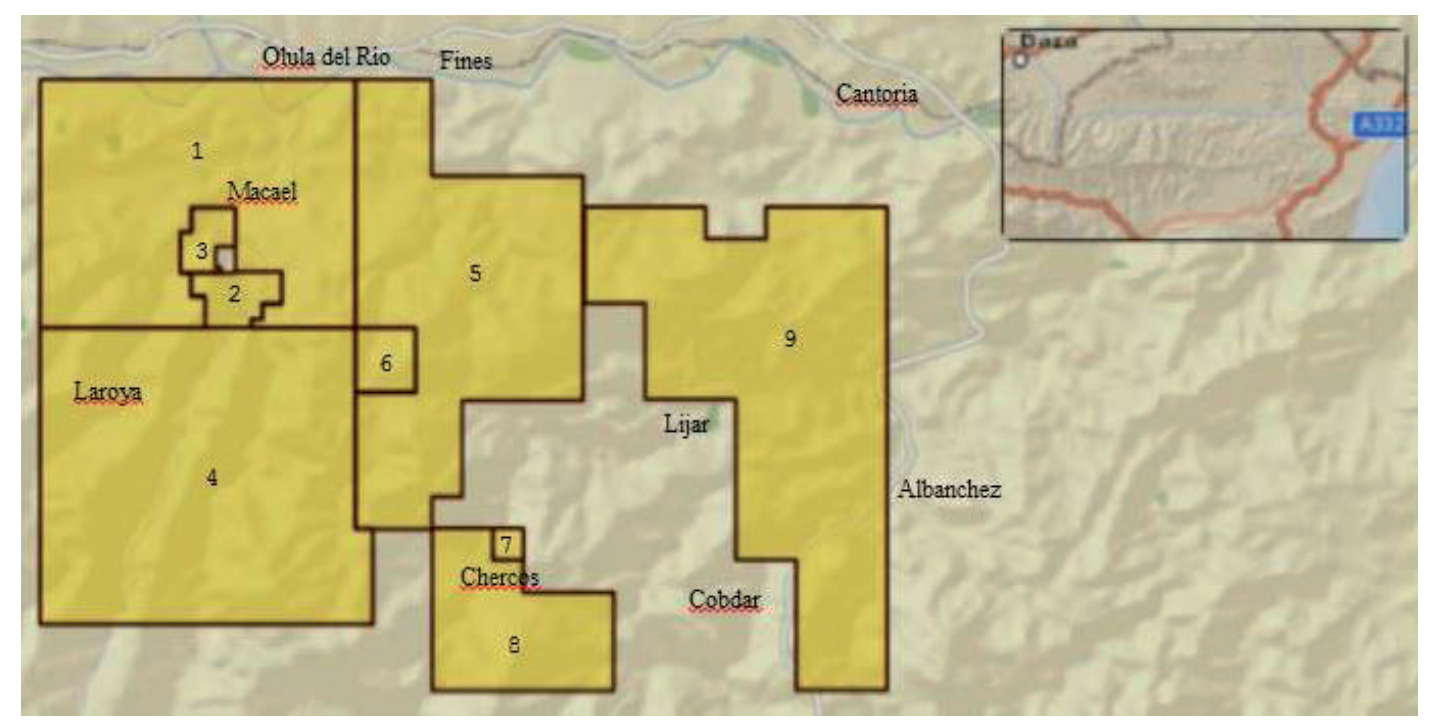

\begin{tabular}{|l|l|l|l|}
\hline & Nombre & Tipo de Derecho Minero & Fecha otorgamiento \\
\hline 1 & Macael Norte & Concesión de Explotación & 27 de febrero de 1981 \\
\hline 2 & La Milagrosa & Concesión de Explotación & 22 de marzo de 1967 \\
\hline 3 & La Segunda Milagrosa & Concesión de Explotación & 7 de abril de 1969 \\
\hline 4 & Macael Sur & Concesión de Explotación & 27 de febrero de 1981 \\
\hline 5 & Macael Este & Concesión de Explotación & 27 de febrero de 1981 \\
\hline 6 & San Andrés & Concesión de Explotación & 3 de febrero de 1995 \\
\hline 7 & Blanco Macael III & Concesión de Explotación & 6 de octubre de 1989 \\
\hline 8 & Blanco Macael & Permiso de Investigación & 21 de junio de 1986 (solic.) \\
\hline 9 & Blanco Macael & Permiso de Investigación & 21 de junio de 1986 (solic.) \\
\hline
\end{tabular}

Figura 3. Derechos mineros titularidad del Ayuntamiento de Macael (2013). Fuente: Registro Minero Nacional. Instituto Geológico Minero de España.

Figure 3. Mining rights are under the ownership of Macael's townhall (2013). 
suyo propio para traspasárselas, revertirán a la administración.

La actividad de las canteras durante las dos últimas décadas del siglo XX está marcada por el Plan de Actuación Global que se inició en la zona en 1983 con el fin de sacar al sector de la grave crisis que estaba atravesando (Barzelay and O'Kean, 1989). El Plan impulsado en sus inicios por el IPIA (Instituto de Promoción Industrial de Andalucía) y continuado después, hasta su finalización a comienzos de los noventa, por el IFA (Instituto de Fomento de Andalucía)contó con el apoyo de todos los agentes del sector y logró que, durante su vigencia, se solucionaran o se encauzaran bastantes de los problemas que venía arrastrando desde antiguo la industria del mármol.

Con la reestructuración industrial impulsada por el Plan, y en particular con la aplicación del Plan Director de la Sierra de Macael, se dio un paso capital para la modernización de las explotaciones. La división de la sierra en unidades de explotación -áreas de características más o menos comunes formadas por varias canteras - permitió una mecanización más racional, mayor continuidad en el suministro de mármol, más orden en las explotaciones y un aumento de la seguridad. En definitiva, un mejor aprovechamiento de las reservas, menores costes de extracción y un alargamiento de la vida del yacimiento (Carretero Gómez, 1995: 345-346). A pesar de todo, el tamaño de muchas canteras sigue siendo insuficiente y además, en varias zonas, los costes de extracción son muy elevados por el volumen de estéril que hay que retirar para acceder a los bancos de mármol.

La lucha por la propiedad de las canteras terminó, mediado el siglo XX, con la sentencia de 1947 de la Audiencia de Granada. La Ley de Minas de 1973 permitió al Ayuntamiento de Macael afianzar los derechos sobre la zona, y el Plan de Actuación Global de la década de los ochenta encauzó muchos de los problemas que arrastraba el sector, aunque, lógicamente, no lo inmunizó ante crisis posteriores. Ahora la batalla se libra en otros frentes de índole productivo y comercial.

\section{Conclusiones}

Durante siglos, y aún en la actualidad, la extracción y elaboración del mármol ha determinado la vida de los habitantes de Macael y sus relaciones sociales y económicas. Frente a intereses de terceros, siempre han defendido que, de una u otra manera, el mármol es suyo. Es perfectamente aplicable al caso la afirmación marshalliana sobre determinados lugares en los que "los misterios de la industria pierden el carácter de tales; están como si dijéramos en el aire y los niños aprenden mucho de ellos de un modo inconsciente" (Marshall, 2005: 318). En Macael se descubren también las características de distrito industrial que, tomando el testigo de Marshall, propone Becattini (1992: 62-64), "entidad socioterritorial que se caracteriza por la presencia activa tanto de una comunidad de personas como de un conjunto de empresas en una zona natural e históricamente determinada". En ese entorno se desarrollan instituciones - que son un reflejo de la sociedad misma: empresas, autoridades locales, partidos políticos, sindicatos y otros organismos públicos y privados, económicos y políticos, culturales y artísticos - y reglas que generan un sistema relativamente homogéneo de valores e ideas, que se trasmiten a las siguientes generaciones.

Los cambios de todo tipo que se han producido a lo largo de los últimos siglos (legislativos, tecnológicos, comerciales) y los lógicos altibajos económicos no han alterado en lo esencial el modus vivendi de Macael, que ha girado alrededor del mármol, sabiendo adecuar en cada momento el modus operandi a las circunstancias de los tiempos.

\section{Agradecimientos}

Este trabajo se enmarca dentro de los Proyectos de Investigación "La minería y su contribución al desarrollo económico, social y territorial de España, 1700-2000. Impacto territorial y legado patrimonial", con referencia HAR2010-21941-C03-03, y "Marco institucional y externalidades en la minería ibérica (siglos XVIII-XXI)", con referencia HAR2014-56428-C3-2, subvencionados por el Ministerio de Ciencia e Innovación.

\section{Referencias}

Aguilera Klink, F. 1987. Los recursos naturales de propiedad común: una introducción. Hacienda Pública Española, 107, 121-127.

Archivo Histórico Provincial de Almería, Diversos documentos.

Archivo Municipal de Baza, Diversas Actas Capitulares.

Archivo Municipal de Macael, Actas de diversas sesiones entre 1819 y 1976 y otros documentos.

Barzelay, M. and O’Kean, J.M. 1989. Gestión Pública Estratégica. Conceptos, Análisis y Experiencias: el caso IPIA. Instituto de Estudios Fiscales, Madrid, 114 pp.

Becattini, G. 1992. El distrito industrial marshalliano como concepto socioeconómico. In: Pyke, F., Becattini, G. and Sengenberger, W. (comp.). Los distritos industriales y las pequeñas empresas, Ministerio del Trabajo y Seguridad Social, Madrid, 61-79 pp. 
Cantó, A.M. 1977-1978. Avances sobre la explotación del mármol en la España romana. Archivo Español de Arqueología, 50-51, 165-189.

Cara Barrionuevo, L. and Rodríguez López, J.M. 1992. Hallazgo de una escultura romana en las proximidades del manantial de aguas termales de Alhama de Almería. Espacio, Tiempo y Forma, Historia Antigua, 1992 (5), 401420.

Carbajo Josa, A. 1994. Legislación española sobre las piedras naturales. In: Grima Cervantes, J. and MartínezCosentino, F. (directores). La piedra natural. Su papel en la historia. Nuevo reto en la minería y en la industria en España, Arráez Editores, Almería, 83-84.

Carretero Gómez, A. 1995. La industria del mármol en Almería. Universidad de Almería, Almería, 383 pp.

Castillo Fernández, J. 1999. Macael y Laroya en la Alta Edad Moderna (1489-1650): conquista, época morisca y repoblación. Instituto de Estudios Almerienses, Almería, 195 pp.

Catastro de Ensenada. 1751. Archivo de la Real Chancillería, Granada.

Chávez Álvarez, M.E., Cámalich Massieu, M.D., Martín Socas, D. and González Quintero, P. 2002. Protohistoria y Antigüedad en el Sureste Peninsular. El Poblamiento de la Depresión de Vera y Valle del Río Almanzora. British Archaeological Report, Oxford, 337 pp.

Estadísticas Mineras, Varios años.

Fernández Carrión, R. 1993. De capital territorial a capital financiero. La conversión de los bienes de propios andaluces en láminas de deuda pública. Editorial Don Quijote, Granada, 190 pp.

González Alcantud, J.A. 1990. Canteros y caciques en la lucha por el mármol. Macael: etnología e historia oral. Instituto de Estudios Almerienses, Almería, 121 pp.
Grima Cervantes, J. 1993. Aproximación a la propiedad de las canteras de la Sierra de Macael en la época morisca y cristiana. Almería y el Reino de Granada en los inicios de la Modernidad (s. XV-XVI). Compendio de estudios. Arráez Editores, Almería, 291-302.

Grima Cervantes, J. 1994. La explotación del mármol de Macael y de Los Filabres a lo largo de la historia (I): Desde la antigüedad hasta el fin del periodo nazarita". In: Grima Cervantes, J. and Martínez-Cosentino, F. (directores). La piedra natural. Su papel en la historia. Nuevo reto en la minería y en la industria en España. Arráez Editores, Almería, 27-42.

Instituto Geológico y Minero de España, Registro Minero Nacional, 15/11/13, http://www.igme.es/infoigme/aplicaciones/rmnweb.

Legislación minera, Diversas leyes y decretos, http://www.boe.es.

Libro de Apeo de Macael. 1573. Archivo de la Real Chancillería, Granada.

Magaña Visbal, L. 1978. Baza histórica. Asociación Cultural de Baza y su Comarca, Granada, 2 tomos.

Malpica Cuello, A. 2002. La Alhambra de Granada, un estudio arqueológico. Universidad de Granada, Granada, $366 \mathrm{pp}$.

Marshall, A. 2005. Principios de Economía. Editorial Síntesis, Madrid, 992 pp.

Otte, E. 2008. Sevilla, siglo XVI: materiales para su historia económica. Fundación Centro de Estudios Andaluces, Sevilla, $371 \mathrm{pp}$.

Pastor Medina, G. 1990. Macael morisco y cristiano. Instituto de Estudios Almerienses, Almería, 130 pp.

Ramos Sánchez, R. and Rodríguez Padilla, E. 2010. República, guerra civil y represión franquista en Macael (Almería) (1931-1947). Arráez Editores, Almería, 406 pp.

Recibido: diciembre 2015

Revisado: febrero 2016

Aceptado: abril 2016

Publicado: junio 2017 
